\title{
A Narrativa Instrumental da Qualidade na Educação
}

VANDRÉ GOMES DA SILVA

USP

\section{RESUMO}

Com base na análise conceitual de usos aparentemente consensuais do termo "qualidade" no campo da educaçáo, o presente trabalho discute a validade do que se denomina aqui narrativa instrumental da qualidade em educação. Essa narrativa se assenta na definição de qualidade restrita a determinados resultados obtidos pelos alunos, quanto ao seu rendimento cognitivo, em avaliações de larga escala, e na utilidade e eficiência que porventura tenham esses resultados, em termos estritamente econômicos. Os pressupostos dessa narrativa instrumental se fundam em fins extrínsecos à própria educaçáo escolar, relegando-a à condição de um simples meio para a satisfaçáo de necessidades antes criadas por uma sociedade de consumo do que legitimamente estabelecidas por uma discussão de caráter eminentemente público e político. É como se o valor da escola pudesse ser estimado pela riqueza ou pelo status social que proporciona aos indivíduos ou pelo desenvolvimento econômico que pode acarretar à sociedade, notadamente desigual em relação aos indivíduos e grupos que a compóem. Desse modo, a formação escolar se vê reduzida a atender a certos interesses socialmente valorizados, supostamente capazes de viabilizar as condiçôes para se obterem mais e melhores resultados, alimentando um fluxo sem sentido.

Palavras-chave: qualidade de ensino, qualidade da educação, sistemas de avaliação, políticas educacionais.

\section{RESUMEN}

Basado en un análisis conceptual de usos aparentemente consensuados del término "calidad" en el campo de la educación, el presente trabajo discute la validez de lo que se denomina aquí narrativa instrumental de la calidad en educación. Esta narrativa se asienta en la definición de calidad restringida a determinados resultados obtenidos por los alumnos, en cuanto a su rendimiento cognitivo, en evaluaciones de gran escala y en la utilidad y eficiencia que por ventura tengan esos resultados en términos estrictamente económicos. Los presupuestos de 
esta narrativa instrumental se fundan en fines extrínsecos a la propria educación escolar, relegándola a la condición de un simple medio para la satisfacción de necesidades creadas por una sociedad de consumo y no legítimamente establecidas por una discusión de carácter eminentemente público y político. Es como si el valor de la escuela pudiese ser estimado por la riqueza o por el status social que proporciona a los individuos o por el desarrollo económico que puede acarrear a la sociedad, claramente desigual en relación a los individuos y grupos que la componen. De este modo, la formación escolar se ve reducida a atender ciertos intereses socialmente valorizados, supuestamente capaces de viabilizar las condiciones para obtener más y mejores resultados, alimentando un flujo sin sentido.

Palabras clave: calidad de enseñanza, calidad de educación, sistemas de evaluación, políticas educativas.

\section{ABSTRACT}

From a conceptual analysis of the apparently consensual use of the word "quality" in the field of education, this paper discusses the validity of what is here called instrumental narrative in education quality. This narrative is based on the definition of quality restricted to certain results achieved by students in terms of their cognitive performance in large-scale evaluations and the usefulness that these results might have in strictly economic terms. The assumptions of such a narrative are based on utilitarian purposes extrinsic to the school education, relegating it to the condition of a simple means for the satisfaction of needs created by a society of consumption rather than needs legitimately established by a discussion of public and political character. It is as if the value of the school could be estimated by the wealth or social status that it gives individuals or the economic development it can provide society with, quite unequal in relation to individuals and groups. Accordingly, school can be seen as solely concerned with socially valued interests, supposedly capable of creating conditions to obtain more and better results, thus fostering a senseless stream of events.

Keywords: quality education, quality instruction, large-scale assessment, educational policies. 
Em um tema como o da qualidade em educação, parece haver um razoável consenso entre as diversas vozes interessadas: o de que estamos imersos numa crise educacional. Os resultados escolares, seus meios de aferição e a discussão que suscitam parecem ser seus indícios mais visíveis, à medida que se identificam diminutas ilhas consideradas "escolas de qualidade", em meio a um mar de outras unidades, notadamente públicas, marcadas por desempenhos classificados como sofríveis e muito aquém do esperado. Há certamente outros indícios, menos objetivos, desse estado de coisas, muitos deles presentes no discurso de boa parte dos professores - por exemplo, as queixas a respeito de uma irremediável "falta de disciplina" dos alunos, dos baixos salários, das condiçôes de trabalho insatisfatórias e da violência dentro das escolas. Essas e muitas outras impressóes, cotidianamente divulgadas, parecem confirmar e estabelecer a evidência da má qualidade da educaçáo como uma conclusão necessária da inegável crise educacional que vivemos.

De fato, a discussão e a análise do tema em questão implicam aceitar um desafio repleto de armadilhas. Talvez a primeira delas seja a de ver no conceito de qualidade um objeto de pesquisa claramente definido, passível de descrição ou, o que é mais comum, da detecção inequívoca de sua falta. Como afirma Bernard Charlot, não é fácil para o pesquisador questionar um problema tal como ele se lhe apresenta, desconstruir e reconstruir esse objeto, menos ainda quando o "objeto aparece amiúde evidente para o próprio pesquisador, o qual se vê preso, como pessoa particular, aos desafios ideológicos que conferem uma aparente consistência ao objeto" (2000, p. 15).

Uma precaução importante pode ser a de desconfiar de formulaçóes, quase inevitáveis, como "o que é educação de qualidade?" ou "a queda na qualidade de ensino se deve a...”. Nesses termos, questóes como essas podem induzir à falsa idéia de que há uma qualidade essencial ou verdadeira em educação, a qual só nos restaria descobrir.

O uso de expressóes como "qualidade da educaçáo" e outras correlatas nada mais é do que um recurso lingüístico, ou um significante ${ }^{1}$, que atribui valor a alguma coisa, conferindo-lhe distinção em função de uma ou mais características suas consideradas superiores ou de excelência. Por exemplo, uma determinada escola pode ter uma série de características facilmente verificáveis, como dispor de oito salas de aula, uma biblioteca, dois coordenadores pedagógicos, um diretor formado em Pedagogia e um corpo docente com formação em nível superior. Uma possível classificaçáo dessa escola como "de qualidade" poderia considerar um fator de dis-

\footnotetext{
${ }^{1} \mathrm{O}$ conceito de qualidade em educação assumiria um papel de "significante, e não um significado", conferindo-lhe um traço peculiar que é o de "adquirir muitos significados" certificados na literatura educacional (Risopatron, 1991, p. 15).
} 
tinção a presença de professores com curso superior, mas essa mesma informação pode suscitar desconfiança e até se converter em elemento de valoraçáo negativa se esses professores forem considerados "mal formados" por terem estudado em faculdades ou universidades de "má qualidade". Ainda que a escola em questáo seja factualmente a mesma, não seria de estranhar que a percepção sobre sua qualidade fosse radicalmente diferente.

Em uso corrente, o termo "qualidade" caracteriza um determinado estado de coisas num sentido positivo. Ao afirmar que "um produto é de qualidade" ou que "uma escola é de qualidade", atribuímos-lhes condição ou situação desejável. Em oposição, algo é considerado de má qualidade na medida em que se distancia daquilo que é esperado ou desejado. Este breve arrazoado nos dá uma idéia do contorno do uso do termo, mas não nos informa sobre aquilo a que se refere, pois a definição e o significado da qualidade de qualquer coisa varia em duas direçóes distintas e concomitantes: de objeto para objeto e de acordo com o contexto histórico em que ele é, por assim dizer, qualificado.

Podemos colher um exemplo disso na visão de parte da população do que seria uma escola de qualidade há 40 ou 50 anos no Brasil. Uma escola "forte", "exigente", preocupada em ensinar aos alunos determinados conteúdos de forma rigorosa e invariável, reprovando implacavelmente aqueles considerados "inaptos" ou "pouco esforçados". Não seria exagero afirmar que, quanto mais uma escola reprovava, mais era considerada de qualidade. É claro que essa concepção convivia com outras, não raro divergentes e contando com mais ou menos adesóes, conforme seus pressupostos e o lugar de onde eram veiculadas e discutidas. Hoje, ainda é freqüente encontrarmos a velha percepçáo de que a boa escola era a "escola pública de antigamente", coexistindo com inúmeras outras visóes do conceito. Ou seja, é comum haver diferentes concepçóes de qualidade em relação a um mesmo objeto, convivendo num mesmo tempo histórico ou um mesmo parâmetro de qualidade aplicado anacronicamente a diferentes contextos históricos.

Não é fortuito que a produção teórica dedicada à análise do conceito de qualidade em educação - em especial, nas duas últimas décadas, por iniciativa de organismos internacionais - revele a perspectiva comum de "um campo altamente problemático de definição e intervenção" (Risopatron, 1991). Essa percepção do problema parece repousar na inegável "existência de muitas definiçôes de qualidade em educação, atestando a complexa e multifacetada natureza do conceito" (Unicef, 2000), além da "confusão conceitual" expressa na literatura educacional pelo "uso abundante de redundâncias e tautologias" em torno da expressão (Adams, 1993). 
Se o uso da expressão "qualidade em educação" pode em algumas ocasiōes nada fazer além de esvaziar o conceito de um significado claramente identificável, em outras parece confirmar a impressáo de que a observação de um determinado objeto é praticamente inseparável da interpretação que dele se faz (Hanson, 1975). Basta imaginar quão diferentes podem ser as visóes da qualidade de uma mesma escola pública por parte de uma família de classe média que recorre a ela, pois seus rendimentos náo permitem o pagamento das mensalidades de uma escola particular, e de outra, mais pobre, cujos pais nem sequer concluíram o ensino fundamental.

Portanto, dizer "essa é uma escola de qualidade" não significa ter descoberto ou comprovado suas características reais, mas interpretá-las com base em certas condiçóes históricas, territoriais, culturais, de classe ou grupo social. $\mathrm{Na}$ medida em que o conceito de qualidade é socialmente construído, importa aqui o modo como se estabelece a relação entre os sujeitos e aquilo que é qualificado. Não se trata de uma propriedade a ser identificada e apreendida na realidade, mas de um ajuizamento de valor a partir da concepção que se tenha de qualidade.

Assim, a qualidade em educação e suas diversas expressóes não constituem um objeto de investigação empírica, mas algo semelhante ao que Charlot (2000, p. 14) denomina "atrativos ideológicos", na análise que faz da expressão "fracasso escolar". As percepçóes tão comuns que atestam um evidente "fracasso escolar" ou a "queda na qualidade de ensino" assumem o papel de "categorias imediatas de percepção da realidade social". Sua condição de objetos de discurso adquire enorme peso social e midiático, uma vez que "são portadores de múltiplos desafios profissionais, identitários, econômicos, sociopolíticos” (Charlot, 2000, p. 14).

Desse modo, seria razoável não tomar a noção de qualidade em educaçáo como auto-explicativa, porque sobre ela repousam muitos e diversos significados e a possibilidade da criação de outros mais. Mas o que ocorre é justamente o contrário, como se vê pela reiterada utilizaçáo da expressão "qualidade" em slogans educacionais, tanto na rede pública como notadamente na rede privada de ensino.

Sob essas condiçóes, uma investigação que se volte a um conceito como esse deve levar em conta uma condição preliminar: a polissemia inerente ao termo "qualidade" e a inevitável ambigüidade que seu uso acarreta. Náo se pode negar que "qualidade em educação" pode significar muitas coisas, e tampouco ignorar que em muitos desses significados há coesão e adequação em função de pressupostos e interesses mais ou menos explícitos. Uma determinada concepção de qualidade parecerá inevitavelmente superior às outras, dependendo da aceitaçáo e adesão a seus pressupostos, interesses e visáo da educação escolar subjacentes. E seria estra- 
nho se fosse diferente. Entretanto, uma análise sob essas condiçôes pode facilmente ceder à tentação de considerar de "maior qualidade" um modelo educacional ou um determinado tipo de escola, considerando critérios particulares a certos grupos ou segmentos sociais, isto é, orientados por interesses alheios à esfera pública.

Por outro lado, a busca de pontos comuns entre os diversos - e às vezes contraditórios - significados de qualidade pode ser um expediente bem intencionado, mas não exatamente profícuo ou abrangente, se deixar de abordar os pontos de discórdia e conflito, mais agudos e fundamentais, e seus condicionantes. Uma análise nesses termos tende facilmente a se deslocar de um âmbito político e ligado ao interesse público para uma discussão de caráter pretensamente técnico e restrito, comumente pautada pela definiçáo dos meios, recursos e metodologias que favorecem uma determinada concepçáo de qualidade previamente estipulada. Dessa forma, a perspectiva de que cada concepçáo de qualidade pode compreender significados distintos em um campo de disputa - não tanto de fatos, mas de conceitos alternativos e não raro excludentes - perde importância ou nem sequer é mencionada ${ }^{2}$. Quando se toma apenas um de seus possíveis significados, é como se a qualidade fosse "neutra" e "universal" (Risopatron, 1991, p. 15).

Torna-se necessário aqui adotar alguns critérios comuns para a análise de diferentes concepçóes em jogo na abordagem do termo, e destacamos menos o caráter de substantivo da palavra "qualidade" do que sua inegável função de adjetivo, que confere algum significado à educação, seja ele qual for. Além de bastante tortuoso, seria enigmático apreender o que se quer dizer com "qualidade", sem abordar o que é de fato substantivo nesta discussão: o que se quer dizer com "educação". Nestes tempos em que cada vez mais prepondera uma visão menos plural e mais determinista do que a instituição escolar pode e deve fazer, é bastante interessante procurar entender o que se quer dizer com "qualidade" e, conseqüentemente, as eventuais concepçóes de educação subjacentes ao uso do termo.

Nesse sentido, a perspectiva de uma análise conceitual (Hirst; Peters, 1972) pode favorecer a reflexão sobre o significado de conceitos presentes nos discursos pedagó-

\footnotetext{
2 Parece ser esse o caso do estudo do Unicef (2000), em que se afirma: "No mapeamento da recente literatura de pesquisa relacionada à qualidade em educação, o Unicef parte de uma ampla perspectiva e demonstra em sua análise que os programas devem abarcar uma definição ampla que envolva alunos, conteúdos, processos, ambientes e resultados” (p. 2), uma vez que "de qualquer forma, há hoje em dia um considerável consenso acerca das dimensões básicas da qualidade educacional” (p. 4). Chama a atenção aí o viés e o tipo de preocupação que orienta o estudo, embora isso de modo algum o desqualifique ou diminua seu interesse em muitos dos temas que aborda.
} 
gicos ou que sejam de interesse do campo educacional - como é o caso de "qualidade" -, os contextos em que são veiculados e as condiçóes de seus usos. Seu foco se volta para a discussão não tanto de uma "realidade" em si, mas da forma ou formas de enxergá-la e suas eventuais conseqüências.

A análise e discussão da qualidade em educação demanda a reflexão sobre seus significados usuais - ao menos os mais comuns -, a verificaçáo de seus pressupostos e de suas pretensóes e a força de sua veiculação; além disso, devem-se explicitar as contendas, as decisóes e as escolhas, ao se lidar com eles. Ao mesmo tempo em que se consideram, por exemplo, as formas pelas quais se fala em qualidade em variados contextos, não se pode perder de vista que alguns valores e objetivos devem prevalecer sobre outros, justamente por se tratar de uma prática social pública realizada pela escola. Assim:

A análise conceptual ajuda-nos a fixar de maneira mais precisa o que está implícito em nossa consciência moral. Mas ela também nos permite afastar-nos um pouco e refletir sobre o status da exigência à qual a palavra testemunha. Ela nos deixa livres para fazer a pergunta fundamental em ética, que é a de se essa exigência é justificada. Na nossa opinião, não vale muito a pena fazer análise conceptual, a menos que alguma questáo filosófica se torne, desse modo, mais manuseável.

Portanto, a primeira coisa a dizer sobre o objetivo de se fazer análise conceptual é que se trata de uma preliminar necessária para responder a algumas outras perguntas filosóficas. Não podemos enfrentar uma questão ética sobre quaisquer boas razóes para se punirem pessoas até que estejamos certos do que queremos dizer com "castigo". Em outras palavras, as questôes de análise muitas vezes estão ligadas a questôes de justificativa. (Hirst; Peters, 1972, p. 20-21)

Sob essa perspectiva, podemos ver no potencial campo de disputa acerca do conceito de qualidade em educação um denominador comum em relação às diferentes concepçóes de educação e seus respectivos parâmetros de qualidade. Esse denominador é a própria configuração da educação escolar como uma prática de caráter público, cujo interesse, aqui, parece ser inversamente proporcional ao sentido preponderante que os discursos em torno da qualidade têm freqüentemente tomado.

\section{A QUALIDADE COMO EFICIÊNCIA}

Por mais gritantes que sejam os problemas que afloram em meio a uma alegada "queda da qualidade de ensino" ou "da educação", sua percepção e causa parecem 
estar fortemente relacionadas ao significado que damos à educação e ao confronto em torno dos pressupostos e repercussóes das concepçóes em jogo.

Supor que "qualidade em educação" seja um conceito tâo independente e "evidente"3 que possa ser dissociado dos interesses e características de uma educaçáo pública significa destituir a expressão de um significado interessante e pertinente à formação de um povo e à construção de sua cidadania.

Há de fato muitos critérios pelos quais se julga ou se caracteriza uma escola de qualidade que, embora sejam amplamente divulgados, não se vinculam imediata ou talvez legitimamente à esfera pública. Para ilustrar alguns tipos de usos da expressão, bastante comuns atualmente, Beisiegel nos oferece um pequeno leque de possibilidades:

Qualidade de ensino é matéria de grande complexidade e sua discussão envolve amplo elenco de questóes. Em diferentes aspectos, alunos, professores, escolas e até mesmo sistemas de ensino têm sido examinados sob o ponto de vista dos respectivos desempenhos: apenas como exemplos, alguns alunos aprendem melhor ou mais rapidamente do que outros; alguns professores ensinam com mais eficiência; conhecem melhor suas disciplinas ou são mais bem aceitos pelos alunos; alguns conteúdos programáticos são mais avançados ou mais extensos do que outros; algumas escolas são mais procuradas, porque os alunos ou seus pais consideram-nas melhores do que outras; o ensino médio público seria menos eficiente do que o particular, etc. Muitas pesquisas, reflexóes, propostas e até mesmo palpites sobre a educação escolar têm focalizado essas e outras questôes que de alguma forma estão relacionadas com o que poderia ser entendido como qualidade de ensino. (2005, p. 7 - grifos nossos)

Num primeiro momento, chama especial atenção nesse rol de perspectivas que, em cada concepção ou entendimento da "qualidade de ensino", se priorizam determinados valores em detrimento de outros. Dessa forma, um professor pode ser mais eficiente ou agradável, um aluno pode aprender com mais rapidez, uma disciplina pode ser mais avançada, algumas escolas podem ser mais desejadas, e escolas parti-

\footnotetext{
${ }^{3}$ Essa auto-evidência teria sido recorrente na análise da literatura sobre a qualidade em educação feita no início dos anos 1990: "Se supõe evidente aquilo que se conhece por demais, como a luz do sol em relação aos objetos que vemos. Ao não abordar uma maior precisão do conceito de qualidade de educação, este continuará sendo evidente, com as conseqüências que acarreta para a implementação de medidas de política educacional que tendem à sua melhora" (Risopatron, 1991, p. 44).
} 
culares são comumente vistas como mais eficientes do que escolas públicas. Uma vez que veiculam valores, tais perspectivas implicam critérios comparativos, ao menos em duas perspectivas distintas. A primeira diz respeito à intensidade com que são percebidos, algo bastante comum em discursos que atestam, por exemplo, que uma escola "tem mais qualidade que outra". Por outro lado, comparaçóes podem ser feitas por meio da exclusão de critérios valorativos considerados indesejáveis, como determinar que escolas de qualidade seriam apenas aquelas que "aprovam seus alunos nos vestibulares mais concorridos", ou então estipular que a qualidade em educação implicaria necessariamente "a adoção de uma gestão democrática". A identificação desses usos do conceito permite determinar o sentido dos valores atribuídos à educação que norteiam uma instituição escolar e em que medida são compatíveis com seu caráter público.

Todavia, há um traço valorativo comum entre muitos desses usos. Se, à primeira vista, percebemos diferentes significados de "qualidade", quando procuramos ordená-los e classificá-los, uma constante se revela. Não é aleatório que o uso do termo esteja limitado ao viés do desempenho, seja de estudantes, professores, escolas ou sistemas de ensino. Nesses termos, é comum que se busque conjugar critérios como comparabilidade e resultado, por assim dizer, de um processo de escolarização, na medida em que "desempenho" designa a execução e o cumprimento de determinada tarefa ou função. Detectar, aferir ou deliberar se dada função foi ou não bem desempenhada são típicos julgamentos distintivos feitos sob o rótulo da qualidade.

É inegável que a noção de desempenho está circunscrita a uma tendência que predomina atualmente, em especial a partir do início dos anos 1990, apontada por Adams (1993) no mapeamento e na análise dos usos mais correntes do conceito em questão em seu trabalho Defining Educational Quality. A ênfase na discussão e proposição de políticas de qualidade da educação estaria relacionada a condiçóes, internas e externas, assim definidas:

Fatores contextuais ou externos incluíram a reação à ênfase da demanda educacional em termos de crescimento quantitativo. Tal ênfase, em geral, falhou ao não atingir as expectativas nacionais predominantes e resultou em muitos "desempregados escolarizados", em meio a mudanças de ordem econômica e tecnológica que demandaram um aumento no nível de habilidades e conhecimentos. $\mathrm{O}$ maior fator educacional interno relaciona-se à escola contemporânea e à pesquisa em salas de aula, criando um senso profissional mais otimista pela sugestão de que as escolas, independentemente de seu contexto socioeconômico, podem ser direcionadas para aumentar a aprendizagem. (p. 3) 
Aplicada ao caso brasileiro, a percepçáo de Adams talvez pareça algo exagerada - pois, no Brasil, além das especificidades e do contexto educacional e social característicos, o enorme contingente de desempregados parece se caracterizar pela pouca escolarização. Todavia, mais do que sua eventual aplicabilidade a determinado país ou tipo de escola, o autor chama a atenção para a ênfase com que se tomam os resultados (outcomes) e produtos (outputs) escolares, assim como os custos e insumos necessários à ampliação ou manutenção da rede escolar (inputs) nas discussóes e análises da qualidade em educação, pautadas pelo inequívoco viés da "eficiência", numa perspectiva conjunta de "planejamento educacional e econômico". Freqüentemente tomados como equivalentes (Risopatron, 1991), essas expressóes situariam a eficiência como o melhor investimento - leia-se "o mais barato" ou "rentável" - para o melhor desempenho obtido pela escola, na medida em que "produtos e resultados [possam] ser especificados e mensurados" (Adams, 1993 , p. 4).

Esse autor descreve ainda outras perspectivas vinculadas à qualidade da educação, relacionadas, por exemplo, ao conceito de processo, compreendendo a "interação entre professores, estudantes, administradores, insumos e tecnologia em atividades educacionais", ou a qualidade como eqüidade (equity), usualmente definida em termos de "oportunidades, distribuição ou conseqüências", cuja falta ou manifestação de forma "injusta" demandariam, além de "políticas eficientes de educaçáo", outras políticas dirigidas a um maior nível de "eqüidade”. Entretanto, são inegáveis o viés e a força da corrente que atrela qualidade a eficiência econômica, e o significado que ganha a percepçáo dos resultados escolares por esse viés.

Não raro, a definição da qualidade em função apenas da eficiência obtida e aferida com base no desempenho escolar, discriminado em determinados produtos e resultados, parece sugerir que comparaçóes entre instituiçóes diferentes - como, por exemplo, uma escola pública de periferia e uma escola particular de elite - poderiam e até deveriam ser feitas a despeito do contexto em que se inserem ou dos pressupostos ou critérios que os animam. Mesmo que se façam ressalvas quanto a eventuais equívocos em comparaçóes desse tipo, o que acaba sobressaindo - e é de fato enfatizado - é a crença na objetividade que determinados resultados escolares podem oferecer. Como destaca Azanha:

A nossa idéia de escola tem sido, muitas vezes, simplificada. Isso se revela, por exemplo, na própria noção de crise educacional que circula amplamente. É comum apontarem-se como evidências da crise alguns resultados escolares como a reprovação e a evasão maciças no $1^{\circ}$ grau, a desarticulação dos diferentes graus 
de ensino, a prevalência de um ensino verbalista que não prepara para o trabalho. Se realmente esses "fatos" são evidências da crise, a nossa concepção de escola é, inegavelmente, fabril, taylorista, porque apenas leva em conta os "resultados" da empresa escolar. E, para sermos coerentes, as nossas "soluçôes" também vêm seguindo a mesma linha; clama-se por processos avaliativos que nos habilitem a detectar pontos de improdutividade para que sua eliminação permita redução de custos e, conseqüentemente, obtenção de maior rentabilidade do sistema escolar. (1995, p. 73)

Não se põe em questão o fato de a prática escolar produzir resultados. Aliás, seria inusitado que após um processo de escolarização, compreendendo as etapas da Educação Básica, por exemplo, não esperássemos alguns resultados, muitos deles óbvios como o aprendizado da leitura, escrita e noçóes de cálculo. Mas outros tipos de resultados esperados de um processo de escolarização podem não ser objetivos ou claramente mensuráveis por meio de exames padronizados. Pense-se, por exemplo, que um "resultado" a ser apresentado pela escola é o de formar cidadãos, ou o de formar pessoas "educadas" ou pessoas "felizes" e o que tais expressóes possam querer dizer.

Dependendo do tipo de resultado ou produto esperado - ainda que possa haver muitos resultados inesperados ou indesejados -, avaliar a qualidade da educação em razão do que ela produz, ou do que possa indicar o que será considerado um desempenho eficiente, pode demandar não só a aferição de seus resultados, mas a avaliação - ou antes a discussão - dos meios pelos quais tais resultados são ou podem ser obtidos e da racionalidade impressa na prática escolar, isto é, o sentido mesmo de uma escola responsável pela formação pública de toda uma população.

Contudo, a ênfase com que se procuram aferir determinados resultados, em termos do desempenho cognitivo de alunos e do impacto que certos aspectos de um processo de escolarização têm no desenvolvimento econômico da sociedade, evidencia uma maior dificuldade em avaliar - ou talvez devêssemos dizer medir quanto a educação escolar favorece ou se relaciona a valores ligados à "formação da cidadania" e a seu livre exercício.

Essa é uma das conclusôes a que chegou o Relatório de Monitoramento Global de Educação para Todos da Unesco (2005), cujo tema foi "O imperativo da qualidade", em que se descrevem dois princípios que caracterizariam "grande parte" das tentativas de se definir qualidade em educação: 
O primeiro [princípio] identifica o desenvolvimento cognitivo dos alunos como o principal objetivo explícito de todos os sistemas educacionais. Conseqüentemente, o sucesso dos sistemas ao realizar este objetivo é um dos indicadores de qualidade. $\mathrm{O}$ segundo enfatiza o papel da educação na promoção de valores e atitudes de cidadania responsável e no provimento do desenvolvimento criativo e emocional. $\dot{E}$ mais difícil avaliar e comparar a realização desses objetivos entre paises. (p. 17 - grifos nossos)

Sublinhe-se o caráter abrangente desse relatório e uma preocupação em mencionar um potencial conflito entre diversas perspectivas em torno da qualidade - o que não significa que tenham sido propriamente discutidas no documento. Embora essa menção seja louvável, ela se configurou antes como um recurso pelo qual se enfatizou determinada perspectiva em detrimento de outras, e isso fica patente quando se afirma, por exemplo, que:

Os resultados devem ser avaliados no contexto dos objetivos estabelecidos. São expressos mais facilmente em termos de rendimento acadêmico (algumas vezes sob a forma de testes), porém com maior freqüência e melhor aceitação, em termos de desempenho em exames, embora também tenham sido elaboradas avaliações de desenvolvimento criativo e emocional, assim como de mudanças em valores, atitudes e comportamentos. Outros indicadores das realizaçóes do aluno e de ganhos sociais e econômicos mais amplos podem ser utilizados - um exemplo é o sucesso no mercado de trabalho. É útil distinguir entre desempenho, conquista e outras medidas de resultados - que podem incluir benefícios mais amplos para a sociedade. (Unesco, 2005, p. 37 - grifos nossos)

Convém lembrar que exemplos baseados em exames acerca de "valores, atitudes e comportamentos" são mencionados de passagem - ao contrário de dois capítulos reservados à análise de desempenho cognitivo e das diversas mençóes a esses tipos de resultado e a seus eventuais impactos, no decorrer das 429 páginas do Relatório.

Nesse documento, o princípio da educação como "promoção de valores e atitudes de cidadania responsável" foi pragmaticamente relegado a segundo plano, seja pela escassez de resultados em termos da mensuração ou avaliação desse princípio, seja pela ênfase na perspectiva do "desempenho em exames" e em como a escola pode propiciar "o sucesso no mercado de trabalho", que ocupou um espaço incomensuravelmente maior. Considerando o foco adotado na análise, a referência às outras dimensôes da educação e de sua qualidade soam como simples ressalvas, cujo 
papel é o de mera figuração ou, quando muito, como aqueles coadjuvantes tão admirados por seus méritos e valores mas que não reúnem as "condiçôes necessárias" para assumir o papel de protagonista da história ${ }^{4}$.

Mesmo quando se questiona - uma pergunta retórica, aliás - se "habilidades cognitivas efetivamente fornecem evidências representativas, ainda que incompletas, da qualidade da escola", isto é, se estariam "relacionadas com o desempenho subseqüente dos estudantes no mercado de trabalho e com a capacidade de crescimento da economia", atestam-se as "crescentes evidências de que a qualidade dos recursos humanos medida por escores de testes é diretamente relacionada a ganhos individuais, produtividade e crescimento econômico" (Unesco, 2005, p. 40).

Como qualquer empresa que sobrevive do consumo, é comum que se tomem alguns resultados dos sistemas escolares amplamente veiculados e socialmente valorizados como o principal parâmetro de sua qualidade e que surjam muitas conclusóes que apontam unidades escolares de maior qualidade - e, portanto, eficientes -, em oposiçáo à grande maioria de escolas de qualidade inferior ou mesmo sem qualidade alguma.

Em que pesem os aspectos característicos e diversos dos vários instrumentos vigentes de medição e avaliação de desempenho dos alunos - como o Saeb, Prova Brasil, Enem -, tais exames náo se destacam apenas por suas peculiaridades, mas também por um propósito comum: de modo geral, há um sentido bastante difundido que concebe a qualidade de ensino ou da educação como um produto que se obtém por meio da escolarização. A despeito das inúmeras perspectivas em que se pode compreendê-los, analisá-los e discuti-los, esses exames são freqüentemente circunscritos ao critério da utilidade, cujo viés inegável é o da satisfação de necessidades e interesses de ordem econômica, e a isso se restringe a sua utilidade social.

\footnotetext{
${ }^{4}$ Lembramos aqui as palavras de Hannah Arendt ao discutir a ação política na modernidade: "não basta fazer certas ressalvas como a de que nem todos os meios são permissíveis ou que, em certas circunstâncias, os meios podem ser mais importantes que os fins, pois tais advertências são feitas à base de um sistema moral aceito a priori e que, como demonstra a veemência das próprias ressalvas, dificilmente poderia ser aceito sem discussão ou então elas mesmas são inválidas pela linguagem e analogia que empregam. Falar de fins que não justificam todos os meios é cair em paradoxo, pois a definição de um fim é precisamente a justificação dos meios, e os paradoxos, embora indiquem perplexidades, jamais as resolvem, e por isso jamais são convincentes" (1995, p. 241).
} 


\section{A QUALIDADE MENSURADA}

Temos visto no Brasil um movimento e uma valorização crescente de políticas de avaliação de sistemas públicos de educação. Por meio de provas em larga escala aplicadas aos alunos, conjugadas a outros instrumentos de coleta de dados, os resultados dessas avaliações são cada vez mais divulgados e, na mesma proporção, tomados como um tipo de descrição mais precisa da realidade e, não raro, da qualidade educacional brasileira.

A estreita relação entre a idéia de qualidade e a forma com que são tomados os resultados de avaliaçóes em larga escala pode ser verificada por uma breve análise do Saeb, recentemente modificado ${ }^{5}$, pela ampla divulgaçáo e visibilidade que ele vem obtendo na última década e também por seu pioneirismo na avaliação de sistemas públicos da educação básica brasileira em proporçóes nunca antes realizadas. Se em seus primórdios, no início da década de 1990, o Saeb visava a "prover informaçóes para a tomada de decisão quanto a diversos aspectos das políticas educacionais e também para pesquisas e discussões, a partir da geração e organização de dados sobre o desempenho acadêmico de alunos no sistema e fatores a ele relacionados" (Gatti, 2002, p. 27), em meados da mesma década, a divulgação dos dados do Saeb - e mais recentemente da Prova Brasil - nos grandes órgãos de comunicação passou a vir associada à idéia de medida da qualidade da educaçáo.

Destacamos algumas manchetes referentes à divulgação de resultados do Saeb e Prova Brasil: "Qualidade de ensino caiu entre 1995 e 2001" (Leale, 2002). A respeito da metodologia do exame, outro jornal diz: "O Saeb, realizado a cada dois anos, visa avaliar a qualidade da educação e verificar que fatores interferem no desempenho dos estudantes" (Góis, 2002), e, na mesma edição, afirma-se que: "Quando são analisados os resultados desde 1995, há uma queda na qualidade do ensino em todas as séries"

\footnotetext{
5 "A partir de 2005, o Saeb passou a ser composto por duas avaliações, a Avaliação Nacional da Educação Básica (Aneb) e a Avaliação Nacional do Rendimento Escolar (Anresc): 1) A Aneb é realizada por amostragem das redes de ensino em cada unidade da Federação e tem foco nas gestões dos sistemas educacionais. Por manter as mesmas características, a Aneb recebe o nome do Saeb em suas divulgações; 2) A Anresc é mais extensa e detalhada que a Aneb e tem foco em cada unidade escolar. Por seu caráter universal, recebe o nome de Prova Brasil em suas divulgações." Nesse sentido, a Prova Brasil - cujo propósito é mais abrangente, por divulgar os resultados por escola e não apenas por sistema, como o Saeb - "adota o marco teórico e os mesmos procedimentos e técnicas do Saeb como, por exemplo, matrizes de referência, testes padronizados para medir o que os estudantes demonstram saber e são capazes de fazer nas áreas de conhecimento, padronização dos trabalhos de campo, uso da Teoria de Resposta ao Item e de Escalas de Proficiência para análise de dados e apresentação de resultados". Disponível em: < http://www.inep.gov.br/basica/saeb/prova_brasil/metodologia.htm > Acesso em: 29 ago. 2007.
} 
(Góis, 2002). No mesmo sentido, vemos a divulgação que se fez da Prova Brasil e de seus resultados - cuja repercussão parece ter obtido mais destaque do que o próprio Saeb: "Cerca de 5,183 milhóes de estudantes de $4^{\mathrm{a}}$ a $8^{\mathrm{a}}$ séries da rede pública farão pela primeira vez neste ano uma prova que permitirá avaliar a qualidade do ensino fundamental e o rendimento do aprendizado por escola e cidade" (Constantino, 2005). Em outra notícia, vemos um exemplo comum de conclusão a que se chega depois de divulgados os resultados: "Os resultados [da Prova Brasil] foram anunciados ontem pelo Ministério da Educação (MEC) e mostram que, na média, o ensino brasileiro está longe de um padrão mínimo de qualidade" (Weber, 2006).

Talvez se pudesse alegar que essa imagem da qualidade da educação escolar associada exclusivamente ao desempenho demonstrado pelos alunos é de responsabilidade exclusiva da divulgação e repercussão promovida pela imprensa, certamente superficial e pouco precisa, e que o objetivo do Saeb e de seus formuladores seria o de medir táo-somente "o nível de aprendizagem" dos alunos brasileiros em Português e Matemática e correlacioná-lo a determinadas condiçóes, extra e intraescolares, que poderiam favorecer ou não a proficiência nessas disciplinas. Nesses termos caberia indagar: medir a proficiência ou rendimento escolar dos alunos é a mesma coisa que medir qualidade de ensino ou da educação?

Parece ser de extrema importância destacar as pretensóes do próprio Saeb como também da Prova Brasil:

O Saeb, criado em 1990, constitui-se em relevante instrumento para subsidiar e induzir políticas orientadas para a melhoria da qualidade da educação brasileira. $\mathrm{O}$ Saeb avalia a qualidade, a eqüidade e a eficiência do ensino e da aprendizagem no âmbito do ensino fundamental e médio. Aplicado a cada dois anos, utiliza testes e questionários para analisar o desempenho dos alunos e os fatores associados a esse desempenho. Os testes utilizados são elaborados a partir das matrizes de referência construídas para a avaliação do Saeb, tendo como base as Diretrizes Curriculares Nacionais, a Lei de Diretrizes e Bases da Educação Nacional (LDB) e as propostas curriculares de todos Estados da Federação. (Brasil, 2002, p. 12 - grifos nossos) A Prova Brasil foi idealizada para produzir informaçóes sobre o ensino oferecido por município e escola, individualmente, com o objetivo de auxiliar os governantes nas decisóes e no direcionamento de recursos técnicos e financeiros, assim como a comunidade escolar no estabelecimento de metas e implantação de açóes pedagógicas e administrativas, visando à melhoria da qualidade do ensino ${ }^{6}$.

${ }^{6}$ Disponível em: <http://www.inep.gov.br/basica/saeb/anresc.htm>. Acesso em: 12 nov. 2006. 
Além da grande coincidência de objetivos entre as duas modalidades de avaliação, os propósitos do Saeb - em que se inspirou posteriormente a Prova Brasil - são mais explícitos ao assumir que avaliam a qualidade do ensino e da aprendizagem ${ }^{7}$. Náo se trata de uma concepçáo isolada. Esse tipo de entendimento da expressáo qualidade de ensino ou qualidade da educação também se encontra em falas, por exemplo, de pesquisadores do assunto, como a que aparece num texto com o sugestivo título "Por uma educação de qualidade". No começo desse artigo, ao enfatizar que as políticas educacionais do Brasil têm por objetivo principal, atualmente, "colocar e manter o aluno na escola", se diz que "A melhoria da qualidade de ensino, no sentido da aprendizagem dos alunos, tem sido relegada a um segundo plano" (Klein, 2003, p. 115-120 - grifos do original). Da mesma forma, Menezes (2007) afirma ser a qualidade da educaçáo "o que se avalia nos exames de proficiência" (p. 27). E se poderiam arrolar muitos outros exemplos como esses.

Evidentemente, as avaliações de rendimento escolar não são destituídas de importância e relevância, principalmente por se tratar de uma prática social de interesse público como a educação escolar, o que só aumenta a necessidade de outro tipo de reflexão e análise que podemos - e devemos - fazer acerca delas. Mas isso não significa que sua utilização tenha ensejado uma mudança significativa na realidade escolar.

Ainda que a utilização dos dados de avaliaçóes em larga escala na formulação de determinadas políticas educacionais tenha sido insuficiente ou mesmo nula, seus possíveis efeitos não se limitariam a isso, sobretudo quando as avaliaçôes sistêmicas se afiguram como sendo elas mesmas a própria tradução de uma política educacional (Oliveira, 2000; Sousa, 2003). Sua relevância recai sobre a própria veiculação do significado daquilo que deve ser a qualidade de ensino, independentemente de eventuais medidas políticas que lancem mão dos resultados obtidos. Evidentemente, não se pode negar o peso que se atribui socialmente à avaliação em um contexto escolar:

\footnotetext{
${ }^{7}$ Embora a definição dada pelo Saeb contenha, em contextos diferentes, expressões semanticamente distintas como "melhoria da qualidade da educação brasileira" e de que esse exame "avalia a qualidade [...] do ensino e da aprendizagem no âmbito do ensino fundamental e médio", tais diferenças são de natureza claramente retórica. É comum que qualidade de ensino e qualidade da educação sejam tomadas como equivalentes, como vimos nas divulgações jornalísticas dos resultados dessas avaliações. No entanto, não deixa de ser interessante que se faça uma distinção entre elas, sobretudo quando a pretensão do Saeb de avaliar "a qualidade do ensino e da aprendizagem" se assenta em pressupostos bastante discutíveis como a certeza de que, pelos resultados apresentados pelos alunos, se pode inferir o tipo de ensino ministrado nas escolas.
} 
Como nossas escolas emergiram sob a égide da preparação das elites, a avaliação seletiva no cotidiano escolar firmou-se, por centenas de anos, como cultura preponderante. Mesmo em momentos nos quais aparecem propósitos de democratização das escolas e os primeiros debates sobre a expansão do sistema de ensino, a cultura que dá forma aos processos avaliativos na escola é a que tem como referência critérios altamente seletivos associados a padróes ditos rigorosos, mas sempre pouco claros. [...] Foi essa cultura que se desenvolveu em torno dos processos avaliativos no cotidiano escolar e que, apesar das amplas discussóes sobre a questão, permanece até hoje, tendo deixado uma forte marca na vida das pessoas e na representação que fazem da avaliação. Então, o fato de os processos avaliativos estarem sempre presentes no ambiente escolar, em todos os níveis, faz com que as pessoas se reportem de imediato a esse tipo de avaliação quando se fala em avaliação educacional, restringindo seu significado. (Gatti, 2002, p. 17)

A ampla discussão e divulgação do assunto pelos meios de comunicação e também pelos agentes da política educacional nos níveis federal, estadual e municipal aponta para uma definição tácita daquilo que se entende por qualidade de ensino ou educação de qualidade. Em função da objetividade com que resultados escolares são divulgados e discutidos, tem-se a nítida impressão de que se sabe qual é o problema a enfrentar e os valores em que nos devemos pautar para reverter a crise educacional, cujo maior indício parece ser a demanda crescente por avaliaçóes. Se a qualidade da educação deve ser entendida como o melhor desempenho dos alunos segundo as matrizes vigentes, tudo o mais que poderia se associar à qualidade parece perder relevância ou, pior ainda, deixa de ser considerado.

Nesses termos, um dos aspectos que mais chama a atenção, no sentido com que se tomam o Saeb e a Prova Brasil, refere-se às matrizes curriculares que servem de base para a elaboração dessas avaliaçóes. A partir de 1995, houve mudanças significativas na metodologia e, posteriormente, nas matrizes curriculares então utilizadas pelo Saeb como parte de um conjunto de medidas implementadas na política educacional brasileira na gestão do Ministro da Educação Paulo Renato Souza (1995-2002). Destacamos, em especial, a introdução da ferramenta metodológica da Teoria da Resposta ao Item - TRI, que, por sua vez, demandou a formulação das matrizes curriculares de referência (1997) com base nas noçóes de competências e habilidades.

A partir de entáo, começou a se consolidar um ponto de referência comum em torno do qual se concentraram as reflexóes e discussóes do significado da qualidade 
de ensino. Poderíamos ter um indício mais claro desse parâmetro de qualidade por meio da definição de "competências cognitivas" e "habilidades instrumentais", cuja posse em relação às disciplinas escolares indicaria um desempenho desejável. Nos termos das matrizes curriculares do Saeb, elas são assim definidas:

Entende-se por competências cognitivas as modalidades estruturais da inteligência - açóes e operaçôes que o sujeito utiliza para estabelecer relaçóes com e entre objetos, situaçôes, fenômenos e pessoas que deseja conhecer. As habilidades instrumentais referem-se especificamente ao plano do "saber fazer" e decorrem diretamente do nível estrutural das competências já adquiridas e que se transformam em habilidades. (Pestana et al., 1999, p. 9)

Um olhar menos atento poderá atribuir à definição de qualidade do Saeb um caráter científico e, por isso, um ar mais confiável, em função da aparente exatidão de suas definições auxiliares de "competências" e "habilidades" (Azanha, 2006, p. 167). Entretanto, mesmo que tais noçôes sejam oriundas de alguma teoria psicológica mais consistente - o que não parece ser o caso ${ }^{8}$-, isso é irrelevante, uma vez que nos vemos diante de uma definiçâo geral, e náo de uma afirmação pertencente a uma rede teórica claramente definida. Além disso, o contexto de uso e divulgaçáo dessa definição não é voltado a uma comunidade científica e tampouco se caracteriza por ser um interesse meramente teórico de descrição e caracterização de determinada realidade. Trata-se, antes, de um instrumento destinado a orientar políticas educacionais e a organização e o sentido das práticas escolares.

Ao se discutir a avaliação da qualidade do ensino ou da educação, nenhuma teoria ou instrumental científico seria capaz de assegurar sua adequação, exatidão ou infalibilidade. Ainda que uma definição de qualidade lance mão de conceitos que possam eventualmente ter integrado alguma teoria psicológica da inteligência, não é seu status teórico ou científico que está em jogo (Scheffler, 1974). Analogamente, tampouco o

${ }^{8}$ Ao analisar o alegado caráter científico das definições propostas pela matriz de competências e habilidades do Enem, Azanha afirma não ser possível "avaliá-las como se fossem definições científicas. Não o são. A referência, no caso das competências, a 'modalidades estruturais da inteligência' é irrelevante do ponto de vista científico, pois é óbvio que, no contexto, essa referência não se vincula a nenhuma teoria explícita de inteligência no corpo da psicologia. Trata-se apenas de encaminhar, aliás confusamente, um propósito para o ensino. É, pois, em termos dos programas práticos que pretendem vincular que essas definições devem ser avaliadas" (2006, p. 165). É interessante notar que as definições de competências e habilidades oferecidas pelas matrizes curriculares do Saeb são muito próximas - e, em certos trechos, idênticas - às do Enem. 
fato de o Saeb ou a Prova Brasil utilizarem procedimentos técnicos sofisticados em sua metodologia e no tratamento estatístico dos dados coletados implica que seus pressupostos ou propósitos sejam técnica ou cientificamente justificados.

O significado de qualidade, entendido como o desempenho ou o rendimento escolar - com base em um conjunto de competências e habilidades que os alunos devem ter -, não é formulado e endereçado a uma comunidade restrita de pesquisa, mas a toda a sociedade - inclusive professores e clientela escolar -, e é nesses termos que ele deve ser analisado. $\mathrm{Na}$ condição de uma definição geral, sua interpretação é política e seu contexto de discussão, análise e julgamento é eminentemente público.

Nesses termos, até que ponto convém reduzir o significado de qualidade de ensino ou da educação ao que os alunos demonstram saber em termos de competências e habilidades nas disciplinas escolares? Não há aí uma mera descrição do que é qualidade. Sua formulação lingüística e o contexto de sua aplicação e veiculaçáo determinam como as coisas ocorrem ou deveriam ocorrer num determinado sentido (Silva; Bauer, 2005). Trata-se de uma concepção pedagógica largamente difundida atualmente que, segundo Azanha, pode ter:

[...] graves conseqüências pedagógicas, principalmente porque, em alguns textos, competências são contrapostas a conhecimentos, como se as escolas de formação geral (ensino fundamental e ensino médio) devessem se preocupar mais com a constituição daquelas do que com o ensino destes, como se fosse possível tornar-se um matemático competente pelo desenvolvimento de uma "coisa" que se chama "competência matemática", distinta do estudo intensivo de tópicos de matemática, ou, da mesma forma, como se fosse possível alguém tornar-se um competente intérprete de Chopin sem o treinamento continuado na execução de suas obras. (2006, p. 181)

Em que pese a confusão conceitual a respeito da noção de competência, pouco discutida e até ignorada pelos agentes institucionais responsáveis pela formulação e implantação das políticas educacionais na ultima década', essa nova opção por de-

\footnotetext{
9 "Fala-se, e com bastante destaque, ainda que nem sempre de forma consistente, na avaliação de competências e habilidades, mas de modo discutível e muito pouco consensual. [...] As questões que se impõem imediatamente, com o objetivo de aprofundar nossas percepções, podem ser propostas da seguinte forma: são desenvolvidas competências e habilidades em nosso sistema educacional de uma forma sistemática, ou, explicitando, é o nosso ensino orientado para o desenvolvimento de competências? Se for, qual a natureza dessas competências e supostas habilidades? Outra pergunta, que também reflete nossa perplexidade: se competên-
} 
terminada perspectiva pedagógica e curricular que melhor delimitasse e orientasse o Saeb e seus critérios para a definição de níveis de aprendizagem a aferir guarda estreita ligação com a formulação dos Parâmetros Curriculares Nacionais - PCN, que começaram a ser formulados e veiculados a partir de 1997 (Brasil, 1999, p. 7).

Reforça-se, assim, um discurso que, para além de eventuais repercussóes concretas e circunscritas a certas açóes, sedimenta um ideário de que o que importa é o produto da escola, passível de ser comprovado e medido em avaliaçóes em larga escala, em estrita correspondência com determinada concepçáo utilitarista de educação, que vê sentido apenas em que o aluno detenha dadas competências e habilidades requeridas pelo mercado de trabalho. Tais questóes referem-se a interesses que se ambientam no debate político acerca do sentido que adquirem as avaliaçóes em larga escala, e não são, como muitos podem supor, uma questáo meramente técnica, mais ainda quando apontam para uma determinada visão e concepção de escola e, conseqüentemente, de sua qualidade.

\section{A NARRATIVA INSTRUMENTAL DA QUALIDADE}

Identificar a qualidade em educação a partir da eficiência com que certos produtos e resultados são - ou não - conquistados é uma forma de defini-la; e definiçóes como essa podem ultrapassar a simples descrição de determinada realidade educacional ou o uso comum atribuído ao termo definido, algo bastante habitual nos discursos pedagógicos. A depender do contexto em que são veiculadas e aplicadas, as definiçôes em educação apontam a diretriz a ser seguida, a orientação pela qual a realidade deve se balizar.

A esse respeito, Scheffler (1974) propóe algumas categorias muito pertinentes à análise da linguagem da educação, com base em uma primeira distinção do que chama de definiçóes gerais presentes no discurso educacional. Estas se dividiriam, primeiramente, em três categorias - estipulativas, descritivas e programáticas -, e cada qual demandaria formas diferentes de apreciação e análise, ocorrendo, inclusive, mais de uma dessas classificaçóes numa mesma definição. Essa dupla avaliação parece se aplicar a muitos casos em que a qualidade da educação é definida pelo

cias e habilidades foram promovidas, houve, efetivamente, preparo adequado dos educadores em relação a esse complexo e controvertido assunto?” (Vianna, 2003, p. 8) “[...] Os programas de pesquisa sobre o Saeb deveriam incluir, necessariamente, uma parte dedicada a estudos de validade, nas suas diferentes modalidades [validade de conteúdo e validade conseqüencial], evitando-se o tratamento tangencial da questão, como vem ocorrendo em alguns poucos trabalhos que discutem a problemática da avaliação.” (p.18) 
desempenho escolar e por seus resultados vinculados prioritariamente a interesses ou necessidades econômicas da sociedade. É freqüente que a ênfase e o viés com que se tomam certos resultados da educação, ainda que espelhem um entendimento comum de certas características inerentes a um processo de escolarização, transcenda a mera descrição de uma dada realidade. Nesses casos, mais do que espelhar um significado bastante habitual atribuído à qualidade, percebe-se a proposição de um programa de açóes. Dessa forma:

[...] é a intenção prática da definição numa ocasião particular que revela o seu caráter programático. Uma mesma fórmula que se repete em várias ocasióes poderá, obviamente, ser programática numa delas e não na próxima. Pode-se talvez dizer, com efeito, que uma definição programática veicula a própria conseqüência prática, não se limitando meramente a exprimir uma premissa capaz de produzir, sob condições adequadas, essas conseqüências. (Scheffler, 1974, p. 29 - grifo do original)

As definições programáticas, alerta Scheffler, são vinculadas a princípios éticos e políticos, uma vez que "tencionam dar expressão a programas de ação" (1974, p. 29). O que está em jogo nesse uso da expressão qualidade de ensino, além do caráter descritivo de um entendimento bastante difundido de como se mede e do que venha a ser qualidade, é o programa de ação e a força prática que essa definição enseja. É esse papel prático, típico das definiçôes programáticas que, a despeito de qualquer medida ou reforma política eventualmente adotada em seu nome, sedimenta e massifica essa concepção de qualidade, inserindo-se de maneira bem direta "nas práticas sociais e nos hábitos de espírito" (1974, p. 28).

Não se pode questionar o discurso educacional e pedagógico por apresentar uma inegável função programática. As definiçóes e, de modo geral, as teorias presentes no campo educacional não se prestam apenas a descrever fatos ou a buscar compreendê-los, mas visam também a transformar uma dada realidade - as teorias que abordam novas metodologias de ensino nas mais diversas disciplinas escolares são exemplos disso. Tampouco as matrizes conceituais do discurso educacional são - ou deveriam ser - apenas de cunho pretensamente descritivo, técnico ou científico, como supóem alguns.

Não deixa de ser também programática a veiculação da idéia de que a educação se deve balizar por pressupostos científicos (Carvalho, 2001) ou econômicos. Isso só evidencia uma característica eminentemente política da prática educacional escolar, numa face característica de seu discurso: a disputa entre conceitos e definiçóes utili- 
zadas em relação a uma mesma expressão ou objeto. A existência de diversos significados atribuídos ao conceito de educação parece ser o exemplo mais contundente disso. Entretanto, vale o alerta de que:

[...] se estamos tentando analisar um conceito, é importante compreender que isso não pode ser feito adequadamente pelo simples exame do uso de palavras de qualquer modo auto-suficiente. Temos que estudar cuidadosamente sua relação com outras palavras e seu uso em diferentes tipos de sentenças. Uma compreensão de seu uso em sentenças não surge apenas estudando-se gramática; também é necessário compreender os diferentes tipos de propósitos ocultos no uso das sentenças, e isso exige reflexão sobre os diferentes propósitos, lingüísticos e nãolingüísticos, que os seres humanos compartilham em sua vida social. (Hirst; Peters, 1972, p. 19)

Nesses termos, é de extremo interesse a abordagem das próprias matrizes conceituais do discurso educacional e as formas de sua apropriação no que tange à análise das definiçôes gerais em educação. Segundo Carvalho (2001), até o final do século XIX, as reflexóes sistemáticas sobre as práticas e os objetivos educacionais foram inspiradas em "doutrinas e concepçóes filosóficas bastante amplas", por exemplo, a visão educacional que se pode depreender de filósofos como Platão e Rousseau. Nessa relação entre cânones da filosofia e a prática educacional, procurou-se derivar dessas doutrinas "desde medidas práticas, como diretrizes de trabalho, até certas perspectivas de políticas educacionais", criando assim um "modelo de discurso pedagógico" cujo pressuposto, em termos práticos, é bastante discutível ${ }^{10}$. A partir do século XX, as "matrizes conceituais do discurso pedagógico" vêm se modificando e tendendo cada vez mais às ciências humanas e, de maneira especial, à psicologia (Carvalho, 2001).

Não se trata de ver uma substituição absoluta de uma matriz filosófica por uma matriz científica, mas de constatar a força e a ênfase com que o discurso pedagógico

10 “As evidências lógicas e empíricas de que não há uma conexão necessária ou um conjunto único de conseqüências derivadas da adoção de certas visões filosóficas amplas e teorias ou reflexões sobre os fins e procedimentos da educação não são desprezíveis. Isso não significa, evidentemente, que não haja relação alguma entres esses dois campos. Apenas torna patente o fato de que os problemas educacionais têm especificidades cujo equacionamento exige muito mais do que uma visão geral de mundo. Há certas características das instituições e dos problemas educacionais cuja compreensão não pode ser lograda por simples analogias ou transposições de conceitos de uma área a outra.” (Carvalho, 2001, p. 20) 
procurou incorporar, em suas definições, um referencial cujo status pudesse ser avalizado por algum ramo da ciência. Talvez os discursos pedagógicos recentes estejam, uma vez mais, mudando sua ênfase, ainda que náo se excluam as outras vertentes de cunho filosófico e principalmente científico.

Percebe-se, assim, a sedimentação de uma visão preponderante - mas evidentemente não exclusiva - do que deve ser entendido por qualidade em educação, cujos princípios convergem para uma determinada razáo meramente economicista para a educação escolar. Essa racionalidade instrumental aplicada à educação não raro se acompanha da fervorosa prescrição de concepçóes de ensino e de aprendizagem orientadas por uma alquimia que agrega expressóes de mal disfarçado caráter pretensamente psicológico - recurso conhecido do discurso pedagógico -, a princípios da Economia e do mundo corporativo.

Reúnem-se diferentes definições que lançam mão de termos como "competências", "habilidades", "competitividade", "necessidades", "eficiência", "cidadania", "produtividade", "desenvolvimento" e outros mais que, analisados isoladamente, podem significar diversas coisas, mas cuja conjunçáo, num grupo de definiçóes que comungam de pressupostos e perspectivas, confere-lhes status e uso característicos, determinantes para a compreensão e a discussão da qualidade em educação sob uma perspectiva bem delimitada.

O que pode estar em jogo, ao voltarmos nossas crenças, esperanças e objetivos da educação escolar a esses deuses modernos - na feliz metáfora de Neil Postman (2002) - travestidos em competências e habilidades inexoráveis do mundo futuro já presentes em nossas vidas? É desejável que a eventual utilidade da escola para o desenvolvimento econômico de uma sociedade - circunscrita e determinada pelo mercado - seja tomada como aquilo de mais valioso e importante a ser feito pela formação de seus habitantes? Sáo justamente os pressupostos e o sentido dessa narrativa impingida à educaçáo escolar, composta de um mosaico de definiçóes que se assemelham ou se complementam, que se destacam ao discutir o caráter de uma educação escolar pública:

Com algumas restriçóes, mas com toda a convicção, emprego o termo narrativa como sinônimo de deus, com $d$ minúsculo. Sei que é arriscado fazê-lo não só porque a palavra deus, tendo uma aura de sacralidade, não deve ser usada levianamente, mas também porque evoca uma imagem fixa. Mas a finalidade de tais figuras ou imagens é dirigir nossa mente para uma idéia e, mais precisamente, para um relato; não qualquer tipo de relato, mas um que fala de origens e visiona um futuro, um relato que constrói idéias, preceitua regras de conduta, 
provê uma fonte de autoridade e, acima de tudo, transmite uma impressão de continuidade e propósito. Um deus, no sentido em que estou usando o vocábulo, é o nome de uma narrativa grandiosa, dotada de suficiente credibilidade, complexidade e força simbólica para nos permitir organizar a vida em torno dela. (Postman, 2002, p. 13)

A discussão de diferentes perspectivas e definiçôes que, em conjunto compóem essa narrativa para a escola, em especial a escola pública, parece indicar precedência sobre quaisquer outras questôes, mesmo que a disposição em fazê-la praticamente inexista no debate educacional atual. Trata-se de voltar à questão dos objetivos a que visa uma educação escolar pública, em busca de sentido em sua razão de ser.

Certamente não padecemos da falta de uma razão pela qual as escolas dêem sentido ao trabalho que realizam (Postman, 2002). Talvez uma das causas de nossa crise educacional resida no fato de existirem diferentes razóes que buscam dar sentido ao trabalho escolar, embora boa parte delas sejam incompatíveis entre si. Mas, como em qualquer boa saga, os deuses vão ganhando força e poder à medida que enfraquecem ou derrotam seus oponentes e, assim, nos deparamos com uma narrativa associada à idéia de qualidade em educação cada vez mais prevalecente e que praticamente procura excluir outras razóes pelas quais se forma um ser humano. Vejamos alguns exemplos de como se vem expressando recentemente no Brasil essa visão, naquilo que tem de mais marcante:

O fiasco da nossa educação fundamental começa a ser percebido. Há cada vez mais brasileiros sabendo que tiramos os últimos lugares no Programa Internacional de Avaliação de Estudantes (Pisa), uma prova internacional de compreensão de leitura e de outras competências vitais em uma economia moderna. (Castro, 2007, p. 9 - grifos nossos)

O significado que possamos ter dessas "competências vitais em uma economia moderna" pode ser um pouco melhor delimitado. Assim, segundo Rose Neubauer da Silva:

A educação, conseqüentemente, passa a ocupar papel central na pauta das políticas públicas governamentais, sendo entendida como uma necessidade estratégica dos países na promoção do desempenho social e econômico de sua população, condição indispensável para obter sucesso na nova ordem internacional, marcada pela grande competitividade entre os países. (1993, p. 19) 
Concepções como essas têm sido crescentemente veiculadas na mídia, na mesma proporção em que se configuram cada vez mais como objeto de discussão e investigação mais especializada. Trata-se de um fim tipicamente utilitarista, de caráter técnico e econômico, atribuído à escola e ao que seria seu papel social. Nesse sentido, a educação tem sua razão de ser no desenvolvimento econômico da sociedade e, portanto, na melhor forma de o futuro cidadáo se adequar a esse modo de vida. Não parece ser outro o motivo pelo qual, no excerto de Cláudio Moura Castro, não são empregados termos como "nação" ou "país" - pois seriam muito pouco interessantes ou pertinentes à idéia de que vivemos numa "economia moderna", que baliza e norteia nosso mundo e nossa sobrevivência.

Nessa perspectiva, a escola, em seus meandros e propósitos, deve se ater a um fim meramente instrumental, voltado para um futuro supostamente inexorável. Essas "novas demandas" para a educação dariam à escola um "perfil mais nítido" e que poderia "ser traduzido como domínio de contextos, desenvolvimento de habilidades cognitivas e de capacidades sociais" (Silva, 1993, p. 20). Cabe perguntar: que habilidades cognitivas desenvolver? Como se definem e ensinam habilidades cognitivas? O que seriam "capacidades sociais"? Seria alguma espécie de formaçáo para o trabalho ou, tendo em conta a dura realidade atual, alguma capacidade especial para se conviver com o desemprego?

Guiomar Namo de Mello (1998) procura explicitar melhor esse novo referencial para a escola, a partir da formulação e adoção do "conceito de satisfação das necessidades básicas de aprendizagem", pela Conferência Mundial de Educaçáo para Todos, realizada em Jomtien, na Tailândia, em março de $1990^{11}$. Esse conceito seria uma orientaçáo "importante para a formulação de políticas, dado o seu caráter objetivo e articulador” (1998, p. 40). Ainda que seja discutível atribuir-lhe um caráter claramente objetivo, o que mais chama a atençáo é a forma como se vai engendrando uma concepção escolar esvaziada de conteúdo, pautada nos chamados "códigos da modernidade".

E as alegadas "necessidades de aprendizagem”, em sua amplíssima formulação, são necessidades individuais, como se, do ponto de vista público e da organização

\footnotetext{
${ }^{11}$ Segundo a Declaração de Jomtien, "Essas necessidades compreendem tanto os instrumentos essenciais para a aprendizagem (como a leitura e a escrita, a expressão oral, o cálculo, a solução de problemas) quanto os conteúdos básicos da aprendizagem (como conhecimentos, habilidades, valores e atitudes) necessários para que os seres humanos possam sobreviver, desenvolver plenamente suas possibilidades, viver e trabalhar com dignidade, participar plenamente do desenvolvimento, melhorar a qualidade de vida, tomar decisões fundamentadas e continuar aprendendo" (Pnud/Unesco, 1991).
} 
do Estado, não houvesse demandas e objetivos tão ou mais valiosos para nortearem a educação. Ainda assim, nessa perspectiva individual, o aprendizado deixa de ser condição de liberdade e se constitui em reino da necessidade. Evidentemente, não de qualquer necessidade, mas daquelas consideradas fundamentais neste mundo ao qual não nos cabe mais do que nos adaptarmos. Desse modo, uma proposta curricular deveria ter:

[...] objetivos cognitivos bastante ambiciosos, menos quanto ao volume de informaçôes específicas e mais quanto ao domínio em profundidade do conteúdo, de modo a desenvolver as capacidades cognitivas de nivel superior que o processo de aquisição do conhecimento deve propiciar. (Mello, 1998, p. 41 - grifos nossos)

Se aqui ainda persiste uma vaga idéia quanto à "profundidade de conteúdo" - embora este venha subordinado ao que supostamente pode oferecer ao mundo do trabalho -, ela vem ganhando, com o passar do tempo, um aspecto mais contundente e o endosso oficial por meio das políticas de reformulação curricular implementadas no Brasil na última década, pautadas pelo domínio de "competências básicas e não no acúmulo de informaçôes", segundo as palavras do ministro da Educação à época da implantação dos PCN (Brasil, 1999, p. 11). Essa compreensão do que deve ser enfatizado no ensino e conseqüentemente avaliado na aprendizagem embasou não só os PCN e as Diretrizes Curriculares Nacionais, mas também as matrizes curriculares do Saeb e da Prova Brasil.

Talvez as pretensóes dos sistemas de avaliação em larga escala de medir a qualidade do ensino tenham encontrado nessa narrativa o arcabouço teórico ideal, uma vez que a qualidade se restringe à eficiência com que certas competências e habilidades podem ser demonstradas ou àquilo que agora se consideram "aprendizagens necessárias":

O conceito de necessidades básicas de aprendizagem é articulador na medida em que focaliza o "núcleo" de todo o processo educativo, ou seja: o ensinoaprendizagem, sugerindo medidas concretas para aferir-lhe a eficiência. (Mello, 1998, p. 40)

A ênfase nesse caráter instrumental da educação, sua tradução na expectativa de os alunos adquirirem discutíveis "competências e habilidades" e a ânsia por avaliaçóes sistêmicas que se atenham a elas - no Brasil e em boa parte do mundo - revelam uma preocupação evidente não só de se detectarem comportamentos, mas também de induzi-los e ditá-los. Tudo em nome de um ideal que não vai além da mera instrução, muito mais do que propriamente algo que poderíamos classificar 
como formação. E isso é concomitante à retórica educacional que costuma acompanhar essa narrativa que, em algumas oportunidades, usa expressóes como "eqüidade social" ou "formação da cidadania", no intuito de legitimar a intenção do discurso. Nesse contexto, tais expressóes são praticamente desprovidas de significado.

De fato, é bastante questionável, por exemplo, a idéia da educação "como elemento central de uma nova estratégia de desenvolvimento, que conjuga a busca de eficiência econômica com a promoçáo da eqüidade e da cidadania”, como pensa Maria Helena Guimarães Castro (1999, p. 6). A menos que a cidadania se deva agora pautar por valores como a competitividade ou exclusão daqueles que são considerados inaptos ao modo de vida que busca prioritariamente o lucro e a premiação "dos melhores" (fundamento indissociável da idéia de competitividade) ${ }^{12}$.

A despeito de quaisquer outras pretensóes que possa ter o trabalho escolar ou mesmo de certos pressupostos que o vêm definindo historicamente, essa narrativa em favor de uma qualidade educacional pautada exclusivamente por determinados produtos da escolarização aponta não só uma razão instrumental que justifique o processo de escolarização, mas atrela esse propósito à forma pela qual as escolas devem encarar seu trabalho e encaminhar os meios a serem empregados no ensino, numa dimensão jamais vista.

Ao mencionar essa categoria que aqui denominamos narrativa instrumental da qualidade em educação, náo pretendemos aplicar fidedignamente os usos canônicos que o conceito de narrativa tem em outras áreas como a Historiografia ou a Literatura, por exemplo, ainda que alguns desses usos, em suas diversas formas, possam relevar aspectos de especial interesse para esta discussão.

Uma narrativa, qualquer que seja, refere-se a alguma experiência, o que lhe confere algum respaldo e identificação por parte do público a que se destina. A experiência narrada náo se restringe ao relato de situaçóes ou feitos únicos e grandiosos, como uma típica narrativa épica ou como um tipo de recorte historiográfico, mas compartilha também um modo de vida, certos valores comungados e cultuados, formas comuns de se verem certas coisas - algo como a imagem do trabalho que a escola deve desempenhar na sociedade -, o que não implica uma descrição objetiva da realidade de um sistema escolar ou do funcionamento de uma determinada escola.

\footnotetext{
${ }^{12}$ Não é demais lembrar a observação de Hannah Arendt a propósito de uma divisão quase física feita no sistema escolar inglês entre crianças mais e menos dotadas: "A meritocracia contradiz, tanto quanto qualquer outra oligarquia, o princípio da igualdade que rege uma democracia igualitária" (2005, p. 229).
} 
Não é tanto a realidade educacional factual que está em jogo nessa narrativa instrumental da qualidade, mas uma "espécie de sentido" orientado pela experiência subjacente à noção de utilidade atribuída ao processo de escolarização, fortemente compartilhada e vivenciada. Na medida em que é constituída por uma amálgama não só de definiçóes gerais mas também de slogans educacionais, essa narrativa não pode ser tomada com um conjunto de afirmaçóes ligadas a um contexto científico e com propósitos teóricos (Scheffler, 1974, p. 20), assim como a noção de "competências e habilidades" não é veiculada por pertencer - eventualmente e de forma discutível - a alguma teoria psicológica claramente definida ou a alguma outra teoria científica. Tampouco se pretendem provar ou discutir seus pressupostos, mas apenas constatar uma posição e direção a serem impressas à prática escolar e à sedimentação de seu significado social, visto que os contextos de seu uso apontam e encaminham um propósito para a educação.

Nesses termos, a exemplo dos slogans educacionais, essa narrativa se circunscreve a um rol de argumentos ou doutrinas literais que a animam e se configura também como a junção de "símbolos que unificam idéias e atitudes-chave dos movimentos educacionais [que] exprimem e promovem, ao mesmo tempo, a comunidade de espírito, atraindo novos aderentes e fornecendo confiança e firmeza aos veteranos" (Sheffler, 1974, p. 46).

Atrelada a essa narrativa instrumental, essa "espécie de sentido" assume uma condição indistinta entre sentido e fim, como sugere Hannah Arendt em sua discussão em torno do conceito antigo e moderno de história. $\mathrm{Na}$ verdade, trata-se de uma "degradação" de sentidos em fins, em que "os próprios fins não são mais compreendidos, de modo que, finalmente, todos os fins são degradados e se tornam meios" (2005, p. 114).

Em última instância, essa "ausência de sentido" teria surgido das filosofias estritamente utilitaristas comuns e características da primeira fase industrial da Modernidade, caracterizada pelo fascínio exercido pelas "novas formas de manufaturar", praticamente impondo aos homens um modo de pensar as coisas em termos de meios e fins. Sua validade viria da origem e da justificação da experiência de produção de objetos-de-uso (Arendt, 2005, p. 114). Assim, o cerne do problema de um significado atribuído à qualidade em educação, restrito a determinados desempenhos esperados de um processo de escolarização, reside:

[...] na natureza do quadro de referência categórico de meios e fins, que transforma imediatamente todo fim alcançado nos meios para um novo fim, como que destruindo assim o sentido, onde quer que este se aplique, até que, no decurso do 
aparente interminável questionar utilitarista - "para que serve..." -, em meio ao aparentemente interminável progresso onde a finalidade de hoje se torna o meio de um amanhã melhor, surge a única questão que nenhum pensamento utilitarista pode jamais responder: "E para que serve servir?" (Arendt, 2005, p. 115)

É como se esse questionar utilitarista, inerente à narrativa instrumental da qualidade, nos convidasse a uma caminhada cujo ponto de partida e as paisagens percorridas fossem desprezíveis em face do ponto de chegada - mesmo que o ponto de chegada seja a inusitada competência e capacidade de caminhar melhor. Os riscos e conseqüências disso já podem ser percebidos: a restrição prática à liberdade das escolas no planejamento e na condução de seu trabalho e, principalmente, a paulatina destituição de outras razóes pelas quais se pode formar um ser humano no âmbito de uma instituição escolar cuja vocação se caracteriza pela iniciação em tradições de conhecimento e formas de vida públicas e não à satisfação de interesses privados.

$\mathrm{O}$ que prepondera atualmente nos discursos educacionais em torno da qualidade na educação é a mera satisfação das necessidades expressas em uma sociedade de consumo, como se nisso consistisse aquilo que de mais importante e valioso podemos ensinar às crianças e jovens recém-chegados ao mundo humano. É como se o valor da escola pudesse ser estimado apenas pela riqueza ou pelo status social que proporciona aos indivíduos ou pelo desenvolvimento econômico que traz à sociedade - de forma notadamente desigual em relação aos indivíduos e grupos que a compóem. É esse o pressuposto de uma narrativa instrumental da qualidade na educação, esvaziada de sentido e voltada a valores individuais e privados, mas não a um interesse que seja efetivamente público, porque comum a todos como expressão maior de formação do cidadão.

\section{REFERÊNCIAS BIBLIOGRÁFICAS}

ADAMS, D. Defining Educational Quality. Arlington, VA: Institute for International Research, 1993. (IED Publicaton: biennial report; 1).

ARENDT, Hannah. A Condição humana. São Paulo: Edusp, 1995. . Entre o passado e o futuro. São Paulo: Perspectiva, 2005.

AZANHA, J.M.P. A pedagogia das competências e o Enem. In: A Formação do professor e outros escritos. São Paulo: Editora Senac, 2006.

. Cultura escolar brasileira. In: Educação: temas polêmicos. São Paulo: Martins Fontes, 1995.

BEISIEGEL, C. A Qualidade de ensino na escola pública. Brasília: Casper Livro, 2005.

BRASIL. Ministério da Educação e Cultura. Saeb 
2001: Relatório Nacional. Brasília: Inep, 2002. $303 \mathrm{p}$.

- Secretaria de Educação Fundamental. Parâmetros Curriculares Nacionais: introdução aos PCN. Brasília: MEC/ SEF, 1997.

BRASIL. Ministério da Educação. Secretaria de Educação Media e Tecnológica. Parâmetros Curriculares Nacionais: ensino médio. Brasília: MEC, 1999.

CARVALHO, J. S. F . Construtivismo: uma pedagogia esquecida da escola. Porto Alegre: Artmed, 2001.

CASTRO, Cláudio Moura. Autópsia do fracasso. Veja. São Paulo, 10 janeiro 2007. n. 1990

CASTRO, Maria Helena Guimarães. A Educação para o século XXI: o desafio da qualidade e eqüidade. Brasília: Inep, 1999.

CHARLOT, Bernard. Da relação com o saber: elementos para uma teoria. Porto Alegre, RS: Artmed, 2000.

CONSTANTINO, Luciana. Ensino fundamental terá prova mirim. Folha de S.Paulo. São Paulo, 23 março 2005. C-1, p. 6.

GATTI, Bernardete A. Avaliação educacional no Brasil: pontuando uma história de ações. EcoS Rev. Cient. Uninove, São Paulo, v. 4, n. 1, 2002. GÓIS, Antonio. Exame mostra queda de nota na $4^{\text {a }}$ série. Folha de S.Paulo. São Paulo, 6 dezembro 2002, C-1, p. 14.

HANSON, R. S. Observação e interpretação. In: MORGENBESSER, S. (org.) Filosofia da ciência. São Paulo: Cultrix, 1975.

HIRST, P. H.; PETERS, R. S. A Lógica da educação. Rio de Janeiro: Zahar, 1972. (Trad.: Edmund Jorge)

KLEIN, Ruben. Por uma educação de qualidade. Ensaio: avaliação e políticas públicas em educação, v. 11, n. 38, p. 115-120, jan./mar. 2003.

LEALE, Francisco. Qualidade de ensino caiu entre 1995 e 2001. O Globo. Rio de Janeiro, 6 dezembro 2002. p.18.

MELLO, Guiomar Namo de. Cidadania e competitividade: desafios educacionais do terceiro milênio. 7.ed. São Paulo: Cortez, 1998.
MENEZES, Naercio. Para além das salas de aula. Cadernos Cenpec, n.3. São Paulo: Cenpec, 2007. (Depoimento prestado no debate Avaliação em educação: o que a escola pode fazer para melhorar seus resultados?)

OLIVEIRA, Romualdo. Reformas educativas no Brasil na década de 90. In: CATANI, Afrânio; OLIVEIRA, Romualdo (orgs.). Reformas educacionais em Portugal e no Brasil. Belo Horizonte: Autêntica, 2000.

PESTANA, Maria Inês Gomes de Sá et al. Matrizes curriculares de referência para o Saeb. Brasília: Inep, 1999.

PNUD/UNESCO/UNICEF/BANCO MUNDIAL. Declaração sobre educação para todos. Plano de ação para satisfazer as necessidades básicas de aprendizagem. Jomtien, 1990 (versão portuguesa). Brasília: Unicef, 1991.

POSTMAN, Neil. OFim daeducação: redefinindo o valor da escola. Rio de Janeiro: Graphia, 2002.

RISOPATRON, Verônica Edwards. El Concepto de calidad de la educación. Santiago, Chile: Unesco/Orealc, 1991.

SCHEFFLER, Israel. A Linguagem da educação. São Paulo: Saraiva, 1974.

SILVA, Rose Neubauer. A qualidade do ensino e a autonomia da escola. In: BORGES, A. S. (coord.) A Autonomia e a qualidade do ensino na escola pública. São Paulo: FDE. 1993. (Série Idéias, n. 16)

SILVA, Vandré G.; BAUER, Adriana. Saeb e qualidade de ensino: algumas questões. Estudos em Avaliação Educacional, v. 16, n. 31, jan./jun. 2005.

SOUSA, Sandra Zákia L. Possíveis impactos das políticas de avaliação no currículo escolar. Cadernos de Pesquisa, n. 119, jul. 2003.

UNESCO. Educação para todos: o imperativo da qualidade. Brasília, DF; São Paulo, SP: Unesco; Moderna, 2005. (Relatório de Monitoramento Global)

UNICEF. Defining Quality in Education. A Paper presented by Unicef at the International Working Group on Education Meeting. Florença, Itália: jun. 2000. 
VIANNA, Heraldo M. Avaliações nacionais em larga escala: análises e propostas. São Paulo: DPE, 2003. (Textos FCC, 23)
WEBER, Demétrio. Escolas do Rio são destaque na Prova Brasil. O Globo. Rio de Janeiro, $1^{\circ}$ julho 2006. p. 13.

Recebido em: junho 2008

Aprovado para publicação em: agosto 2008

Vandré Gomes da Silva é mestre e doutor em educação pela Universidade de São Paulo (vandregs@ig.com.br). 